\title{
STUDIES ON THE ACTIVATION OF ORGANIC ARSENICAL COMPOUNDS (PART II)
}

\section{SHIGESHI TOYOSHIMA}

The Pharmaceutical Institute, School of Medicine, Keio University

(Received on April 20, 1952)

\section{Introduction}

Concerning the mode of action of organic arsenical compounds it has been considered, heretofore, that they invade SH-enzymes of the parasite and the human body tissue in coformity with the chemotherapeutic interference of $\mathrm{SH}$ compounds such as Glutathione and cysteine hydrochloride. However, a phenomenon which

Table 1

The infuence of various second components against the anti-trypanosoma action and the toxicity of $\mathrm{OxO} \cdot \mathrm{HCl}$

\begin{tabular}{l|c|c}
\hline \hline name of various second components & $\begin{array}{c}\text { minimal effective dose } \\
(\mathrm{mg} / \mathrm{kg})\end{array}$ & $\begin{array}{c}\text { maximal tolerative dose } \\
(\mathrm{mg} / \mathrm{kg})\end{array}$ \\
\hline 1. Oxo-HCl alone & 2.08 & 33.3 \\
2. Oxo-HCl+glucose & 1.78 & 38.4 \\
3. Oxo-HCl+vitamin $\mathrm{B}_{1}$ & 1.66 & 35.7 \\
4. Oxo-HCl-vitamin $\mathrm{B}_{2}$ & 2.5 & - \\
5. Oxo-HCl+vitamin $\mathrm{B}_{6}$ & 1.78 & 33.3 \\
6. Oxo-HCl+vitamin C & 1.56 & 38.4 \\
7. Oxo-HCl+sodium thiosulfate & 1.78 & 33.3 \\
8. Oxo-HCl+glycine & 1.78 & 35.7 \\
9. Oxo-HCl+leucine & 1.78 & 33.3 \\
10. Oxo-HCl+cystine & 1.78 & 33.3 \\
11. Oxo-HCl-methionine & 1.78 & 35.7 \\
12. Oxo-HCl+taurine & 2.5 & - \\
13. Oxo-HCl-tyrosine & 1.47 & 35.7 \\
14. Oxo-HCl+histidine & 1.66 & 35.7 \\
15. Oxo-HCl+sodium glutaminate & 1.43 & 35.7 \\
16. Oxo-HCl+tryptophan & 1.38 & 35.7 \\
17. Oxo-HCl-anthranilic acid & 1.38 & 35.7 \\
18. Oxo-HCl+benzoic acid & 2.5 & - \\
19. Oxo-HCl+salicylic acid & 2.5 & - \\
20. Oxo-HCl+p-aminobenzoic acid & 1.78 & - \\
21. Oxo-HCl+procaine & 1.78 & - \\
22. Oxo-HCl+tutcaine & 1.78 & - \\
\hline
\end{tabular}


contradicts these chemotherapeutic interference, namely, the existence of a substance which will increase the efficiency of organic arsnical compounds, has hardly been recongnized.

The author, therefore, in Part I of this report series(1), upon examining the effects of 21 substances against Oxophenarsine Hydrochloride (Oxo-HCl) and attaining the result as of table 1 , has discovered that aromatic amino acid, especially tryptophan, anthranilic acid and sodium glutaminate possess a nature which increases the anti-trypanosoma-action of Oxo-HCl.

$\mathrm{Ir}_{1}$ this report, the author, therefore, has again continued to examine protein, especially plasma protein fractions and observed its effects against the antitrypanosoma-action and toxicity of Oxo-HCI, and moreover, has made obvious the inhibitory action of Oxo-HCI against plasma and red blood cell cholinesterase, and also made clear that the toxicity of $\mathrm{Oxo}-\mathrm{HCl}$ is caused by this inhibitory action against cholinesterase.

Thus, the author has noted the anti-cholinesterase-action of anti-trypanosomaaction and the toxicity of Oxo-HCI, and has reached some new knowledge which will be given below:

2. Concerning the effect of plasma protein against the anti-trypanosoma-action and the toxicity of Oxo-HCl. Method of experiment:

For plasma, normal horse plasma was used, divided further into albumin, eu-globulin, and pseudo-globulin by using ammonium sulfate. This plasma and plasma protein fractions were mixed with $\mathrm{Oxo}-\mathrm{HCl}$ and used. For animal, mice of $13-15 \mathrm{~g}$ in weight were used; for parasite, Trypanosoma gambiense was used. To decide its efficiency, the minimal effective dose was determined after 14 day's observation for the toxicity, minimal tolerative dose was decided after 4 days observation.

As shown in Table 2, plasma increases the efficiency of Oxo-HCI at times and decreases it at others. This is related to the quantity of plasma used: when small amount is used, it increases the efficiency of $\mathrm{Oxo}-\mathrm{HCl}$ : when too much is used, it will, on the contrary, lower the efficiency of Oxo-Hal.

From this fact, it can be deduced that there exists in the plasma a fraction which increases the efficiency of Oxo-HCl and fractions which decrease it. The fraction which increases the efficiency of $\mathrm{Oxo}-\mathrm{HCl}$ is eu-globulin and fractions which decrease it are albumin and pseudo-glodulin.

The efficiency-increasing action of eu-globulin upon Oxo-HCl is extremely 
Table 2

The infuence of plasma and plasma protein fractions against the antitrypanosoma-action and the toxicity of $\mathrm{OxO}-\mathrm{HCl}$

\begin{tabular}{l|c|c|c}
\hline \multicolumn{2}{c|}{ Plasma and plasma protein fraction } & $\begin{array}{c}\text { minimal effective } \\
\text { dose }\end{array}$ & $\begin{array}{c}\text { maximal tolerative } \\
\text { dose }\end{array}$ \\
\hline \multicolumn{1}{c|}{ name } & $\begin{array}{c}\text { dose }=\mathrm{mixd} \text { with } \\
2.3 \mathrm{mg} \text { Oxo-HCl }\end{array}$ & $\mathrm{mg} / \mathrm{kg}$ & $\mathrm{mg} / \mathrm{kg}$ \\
\hline 1. Oxo-HCl alone & & $2.5 \mathrm{mg}$ & 33.3 \\
2. Oxo-HCl+plasma & $5.0 \mathrm{cc}$ & 5.0 & \\
3. Oxo- $\mathrm{HCl}+$ plasma & $1.0 \mathrm{cc}$ & 1.38 & \\
4. Oxo-HCl+albumin & $40.0 \mathrm{mg}$ & 10.0 & \\
5. Oxo-HCl-pseudo-globulin & $10.0 \mathrm{mg}$ & 5.0 & \\
6. Oxo-HCl-eu-globulin & $1.0 \mathrm{mg}$ & 1.11 & \\
7. Oxo-HCl+eu-globulin & $2.5 \mathrm{mg}$ & 2.5 & 40.0 \\
8. Oxo-HCl+eu-globulin & $5.0 \mathrm{mg}$ & 2.5 & \\
\hline
\end{tabular}

Fig. 1. The time required to extinguish Trypanosoma gambiense from the blood stream of mice after the injection of $\mathrm{Oxo}-\mathrm{HCl}$ alone or $\mathrm{O} \times-\mathrm{HCl}+$ eu-globulin.

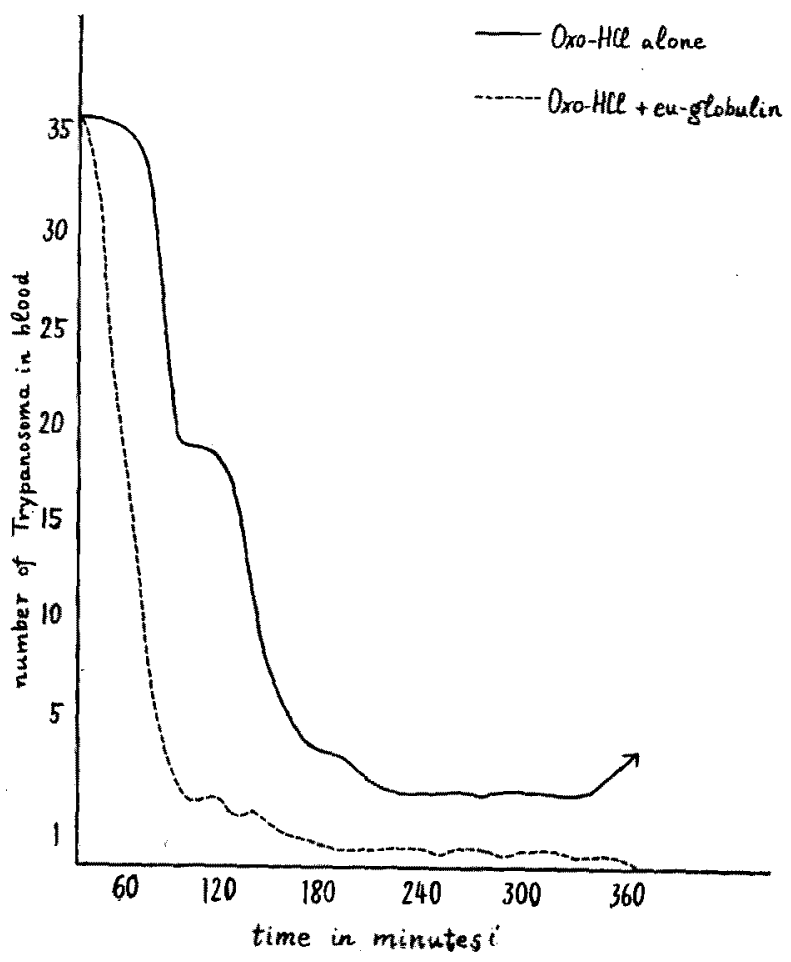


strong and the time required to extinguish trypanosoma gambiense from the blood stream of mice after the injection of $\mathrm{Oxo}-\mathrm{HCl}+$ eu-globulin is much shorter than Oxo-HCl alone (Fig. 1). The increasing action of eu-globulin upon the efficiency of Oxo-HCl requires some time after mixing for reaction: no marked activation: can be observed immediately after mixing, 5 minutes after mixing or 10 minutes after mixing, but by leaving it to react for 15 minutes this action of eu-globulin can be observed obviously.

From this fact comes the deduction that a loose combination occurs between $\mathrm{NH}$ group of $\mathrm{Oxo}-\mathrm{HCl}$ and separate $\mathrm{COOH}$ group of amino acids which construct protein.

The action of eu-globulin which lowers the toxicity of $\mathrm{Oxo}-\mathrm{HCl}$ is slightly weak compared to the action which increases its efficiency and M.L.D. is reduced a little. As a result, the chemotherapeutic index of Oxo-HCl increases nearly three times by the addition of eu-globulin.

3. The inhibitory action of Oxo-HCl against blood cholinesterase and the toxicity decreasing action of anti-histamine drug against Oxo-HCI.

It has already been determined by Gordon and Quastel ${ }^{(2)}$ that Oxo-HCI is the inhibitor against cholinesterase, but the author has used human red glood rell cholinesterase for specific cholinesterase, and horse plasma or human plasma cholinesterase for nonspecific cholinesterase, and thereby examined the inhibitory action of Oxo-HCI.

Method of experiment:

The activity of red blood cell cholinesterase was measured according to Warburg's manometer ${ }^{(3)}$ : the activity of plasma cholineterase was measured by Holl and Lucas's method ${ }^{(4)}$. The effect of anti-histamine drugs and SH compounds against the anti-trypanosoma action and the toxicity of $\mathrm{Oxo}-\mathrm{HCl}$ was determined as described above. Result of experiment:

The inhibitory action of $\mathrm{Oxo}-\mathrm{HCl}$ against red blood cell cholinesterase does not show any exceptional action when $3 \mathrm{mg}$ or $6 \mathrm{mg}$ of Oxo- $\mathrm{HCl}$ is mixed with $2.0 \mathrm{cc}$ of human red blood cell suspension, but when $12 \mathrm{mg}$ is mixed, about $22 \%$, and when $24 \mathrm{mg}$ is mixed, up to $50 \%$ lowering of the activity may be determined. The inhibitory action of Oxo-HCl against plasma cholinesterase when $3 \mathrm{mg}$ of Oxo-HCl is mixed with $2.0 \mathrm{cc}$ of plasma is $17 \%$, with $5 \mathrm{mg}, 26 \%$, with $10 \mathrm{mg}, 27 \%$, with $20 \mathrm{mg}, 29 \%$, with $30 \mathrm{mg}, 35 \%$, with $40 \mathrm{mg}, 40 \%$, lowering of the activity may be determined (Table 3 ).

From the above, it can be considered that Oxo-HCl shows some degree of 
Table 3

The inhibitory action of $\mathrm{OxO}-\mathrm{HCl}$ against blood cholinsterase

(A) in vitro test.

\begin{tabular}{|c|c|c|c|}
\hline Cholinesterase & $\begin{array}{l}\text { Dose of Oxo-HCl } \\
\text { added to plasma } \\
\text { (or RBC) } 2.0 \mathrm{cc}\end{array}$ & activity of enzyme & $\begin{array}{l}\text { inhibitory } \\
\text { percent }(\%)\end{array}$ \\
\hline plasma cholinesterase & normal plasma alone & $3.11(\mathrm{cc})$ & \\
\hline$"$ & $40.0 \mathrm{mg}$ & 1.94 & 48 \\
\hline " & $30.0 \mathrm{mg}$ & 2.04 & 34.4 \\
\hline$"$ & $20.0 \mathrm{mg}$ & 2.22 & 28.9 \\
\hline " & $10.0 \mathrm{mg}$ & 2.26 & 27.3 \\
\hline$"$ & $5.0 \mathrm{mg}$ & 2.29 & 26.3 \\
\hline red blood cell & & normal test & \\
\hline cholinesterase & $24 \mathrm{mg}$ & $382 \mathrm{cmm} \quad 194 \mathrm{cmm}$ & 46 \\
\hline$"$ & $12 \mathrm{mg}$ & $354 \quad 274$ & 22 \\
\hline$"{ }^{i}$ & $6 \mathrm{mg}$ & 214 & 7.5 \\
\hline$"$ & $3 \mathrm{mg}$ & 364 & 0 \\
\hline
\end{tabular}

(B) in vivo test (Rabbit)

\begin{tabular}{|c|c|c|c|c|c|c|c|c|c|c|}
\hline & \multirow{2}{*}{$\begin{array}{c}\text { dose } \\
(\mathrm{mg} / \mathrm{kg})\end{array}$} & \multirow{2}{*}{$\begin{array}{c}\text { before } \\
\text { injection }\end{array}$} & \multicolumn{8}{|c|}{ after injection } \\
\hline & & & $\begin{array}{c}1-2 \\
\text { minute }\end{array}$ & $\begin{array}{c}5 \\
\text { min. }\end{array}$ & $\begin{array}{c}15 \\
\text { min. }\end{array}$ & $\begin{array}{c}30 \\
\min \end{array}$ & $\begin{array}{c}45 \\
\min .\end{array}$ & $\begin{array}{c}60 \\
\mathrm{~min} .\end{array}$ & $\begin{array}{c}90 \\
\text { min. }\end{array}$ & $\begin{array}{l}120 \\
\text { min. }\end{array}$ \\
\hline $\mathrm{Oxo}-\mathrm{HCl}$ & $16 \mathrm{mg}$ & $1.01 \mathrm{cc}$ & 4 & $\because$ & 0.64 & & & 0.66 & 0.56 & 0.57 \\
\hline$"$ & $"$ & 0.97 & & & 0.69 & & 0.59 & 0.61 & 0.63 & 0.63 \\
\hline$"$ & $"$ & 0.99 & & 0.69 & 0.66 & & & 0.66 & & 0.64 \\
\hline '" & " & 0.87 & 0.51 & 0.40 & & 0.45 & & 0.45 & & \\
\hline " & $"$ & 0.80 & 0.45 & 0.40 & & & & & & \\
\hline $\mathrm{Oxa}-\mathrm{HCl}$ & $16 \mathrm{mg}$ & 0.78 & 0.67 & 0.73 & & & & & & \\
\hline +Cysteine $200 \mathrm{mg} / \mathrm{kg}$ & $"$ & 0.86 & & 0.63 & 0.62 & & & & & , \\
\hline " & t & 0.99 & & 0.88 & 0.85 & & & & & \\
\hline $\mathrm{OxO}-\mathrm{HCl}$ & $16 \mathrm{mg}$ & 0.81 & 0.73 & 0.73 & 0.75 & & 0.74 & & & \\
\hline +Benadryl $4 \mathrm{mg} / \mathrm{kg}$ & $"$ & 0.81 & 0.74 & 0.74 & 0.77 & & 0.76 & & & \\
\hline$"$ & $"$ & 0.79 & 0.70 & 0.69 & 0.75 & & 0.74 & & & \\
\hline
\end{tabular}

inhibitory action against blood cholinesterase, and that not necessarily all, but perhaps a considerable part of the side reaction of $\mathrm{Oxo}-\mathrm{HCl}$ is caused by the inhibition of cholinesterase.

Secondly, when testing the inhibitory action of Oxo-HCl against cholinesterase by mixing cysteine and Banadryl, it was found out that in the case of cysteine, the inhibitory action of Oxo- $\mathrm{HCl}$ against cholinesterase is contradicted and in the case of Benadryl this action of $\mathrm{Oxo}-\mathrm{HCl}$ is contradicted seven more severely than with cysteine (Table 3). Therefore, it is inferable that the toxicity of Oxo-HCl can, by using anti-histamine drug, be lowered much more powerfully than by 
using cysteine. The anti-histamine drugs used in this experiment were Benadryl and pyribenzamine and as $\mathrm{SH}$ compounds, BAL, Cysteine and glutathione were used. The dose of Benadryl and pyribenzamine is small compared to $\mathrm{BAL}$, cysteine and Glutathione, yet the action which lowers the toxicity of Oxo-HCl is, in the case of both benadryl and pyribenzamine, matched with that of BAL and better than in the case of cysteine and glutathione (Table 4). Moreover, the efficiency of Oxo-HCl is markedly lowered by the mixture of $\mathrm{SH}$ compounds, whereas with anti-histamine drug, although it lowers the efficiency of Oxo-HCl to some extent, when compared with the former by chemotherapeutic index, ultimately, it can "be said that anti-histamine drug is superior to $\mathrm{SH}$ compounds as the toxicity reducing drug.

Table 4

The influence of anti-histamine drug and SH compound against the anti-trypanosoma action and the toxicity of $\mathrm{Oxo}-\mathrm{HCl}$

\begin{tabular}{l|c|c|c}
\hline \hline name of second components & dose $(\mathrm{mg} / \mathrm{kg})$ & $\begin{array}{c}\text { minimal effecitive } \\
\text { dose }(\mathrm{mg} / \mathrm{kg})\end{array}$ & $\begin{array}{c}\text { maximal tolerative } \\
\text { dose }(\mathrm{mg} / \mathrm{kg})\end{array}$ \\
\hline 1. Oxo- $\mathrm{HCl}$ alone & & 2.5 & 33.3 \\
2. Oxo-HCl+BAL & 40 & 10.0 & 50.0 \\
3. Oxo-HCl+Cysteine & 200 & 2.5 & 40.0 \\
4. Oxo-HCl+Glutathione & 100 & 5.0 & 40.0 \\
5. Oxo-HCl+Benadryl & 4.0 & 5.0 & 50.0 \\
6. Oxo-HCl+Pyribenzamine & 3.0 & 2.5 & 50.0 \\
\hline
\end{tabular}

4. Summary

(1) By studying the action of plasma against Oxo-HCl, it has been discovered that plasma increases or decreases its efficiency according to the quantity used.

(2) This fact allows the presumption that there exists, in plasma protein fraction, a part which increases its efficiency and parts which decrease its efficiency. This efficiency increasing part is eu-Globulin; the efficiency decreasing parts are albumin and pseudoglobulin.

(3) With the addition of eu-globulin the efficiency of Oxo- $\mathrm{HCl}$ is increased, the toxicity is decreased slightly, and the chemotherapeutic index grows 3 times as that of Oxo- $\mathrm{HCl}$ alone.

(4) This action of eu-globulin requires some time for reaction after mixing. From this fact it is inferable that a compound is found by a loose combination between $\mathrm{Oxo}-\mathrm{HCl}$ and the separate acid group of the amino acid constructing eu-globuline. 
(5) Oxo-HCl obstructs red blood cell cholinesterase, and also inhibits plasma cholinesterase. From this fact, it is deduced that one cause for side reaction of Oxo-HCl might lie in the inhibitory action against cholinesterase.

(6) When cysteine or Benadryl is mixed with $\mathrm{Oxo}-\mathrm{HCl}$, the inhibitory action against cholinesterase is decreased. From this, it is thought that anti-histamine drug passosses an action which markedly lowers the toxicity of Oxo- $\mathrm{HCl}$.

(7) The action of anti-histamine drug (Benadryl and pyribenzamine) which lowers the toxicity of $\mathrm{Oxo}-\mathrm{HCl}$ is superior to that of cysteine and glutathione, and is equal to that of BAL. And, as the action which lowers its efficiency is less than that of SH compounds, the author thinks, the anti-histamine drug are to be given proper attention as the toxicity reducing drug against Oxo-HCI.

Acknowledgement. The author is indebted to T. Mizuma and K. Takahashi for chemical experiments.

\section{REFERENCES}

1. Toyoshima, S.: J. of Chemotherapy and Hormone Therapy 1, 302, 1948. (Japanese)

2. Gordon, Suastel: Nature. 159, 97, 1947.

3. Tamai, A.: J. of Japanese Biol. Chem. 22, 32, 1950.

4. Holl, Lucas: J. of Pharmacol. 59, 34, 1937. 